\title{
Research on the Cultural Brand Branding Strategy in Fujian Free Trade Area
}

\author{
Juan Guo ${ }^{1, \text { a }}$ Wenchao Du*1, b \\ ${ }^{1}$ Xiamen University Tan Kah Kee College, Zhangzhou, Fujian, China, 363105 \\ aemail, bemail,
}

Keywords: Free Trade Area, Strategy Research, Cultural Branding, In Localization

\begin{abstract}
Based on the new model of consumer psychology ----- AIGAS model, this paper constructs the cultural brand of FTA in Fujian province. Through the cultural rebirth strategy, the cultural transformation strategy of Taiwan culture marketing mode, the multi-media marketing strategy, Fujian local culture output strategy to build a complete AIGAS brand model, from the strategic height of the image of the Fujian FTA accurate positioning in the process of internal and external communication to maintain a unified and complete brand image of Fujian FTA, Fujian Province to enhance the self- Trade Area, the influence of cultural brand at home and abroad, from the Free Trade Area in Fujian Province to enhance the value of cultural brands to provide assistance
\end{abstract}

\section{Introduction}

From the previous survey of data from the Shanghai Free Trade Area data, the General Administration of Customs data show that in the first half of 2014, Shanghai's trade in services increased by 15\% over the same period last year, an increase of 9 percentage points higher than the trade of goods. Among them, only the foreign trade base of Waigaoqiao foreign trade base trade volume reached 32.8 billion RMB, an increase of 2.83 times. As of the end of 2015, located in the Shanghai FTA foreign trade and trade base of the art of bonded warehouses, driven by the total value of imports and exports has been as high as 15 billion RMB. As of May 2016, the state's foreign cultural and trade base settled in various cultural enterprises accumulated more than 400 . According to (Figure 1) shows that cultural brand is an important support for the development of cultural industries and cultural province is an important symbol. Only in the construction of Fujian Free Trade Area at the beginning of shaping the brand image of the FTA, in order to make the Fujian Provincial Free Trade Area cultural brand consumer market in a healthy, orderly and sustainable direction, so that Fujian has become a strong cultural Province, and the Fujian Free Trade Area to create a unique cultural brand of free trade area.

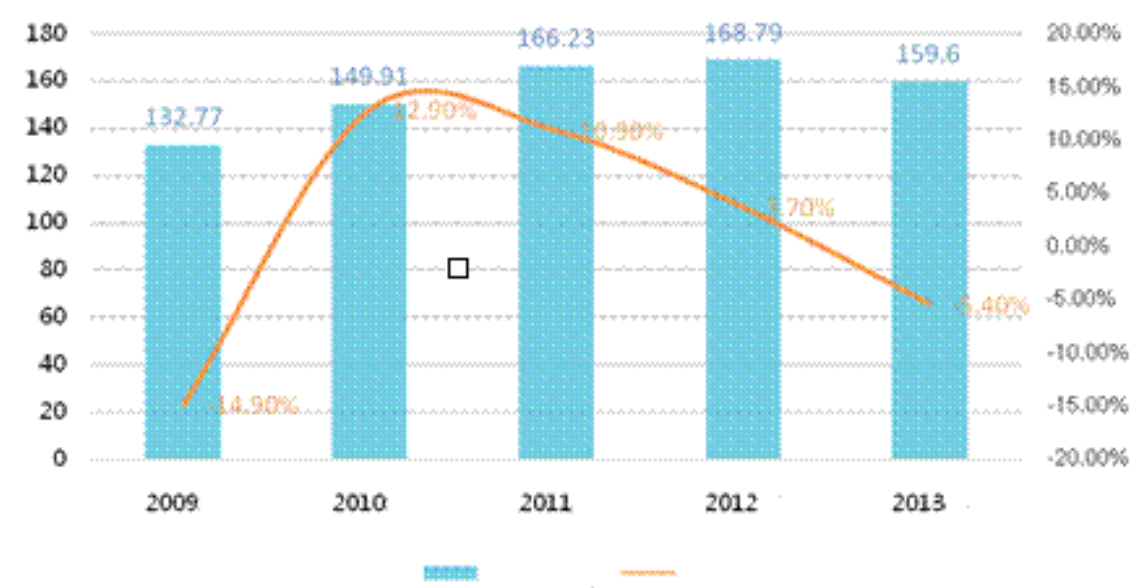

Figure 1, from the 2014 Shanghai foreign trade and trade development report data sheet

Fujian Free Trade Area is approved by the second batch, including Xiamen, Pingtan, Fuzhou three area, covers an area of 118.4 square kilometers, scattered in different cities, the larger span. At 
present, the research on the free trade area shows that there are few researches on the economic and border trade research and the research on the cultural brand system of the FTA. Free trade area in Fujian Province is in addition to the introduction of trade, as an important window of foreign trade in Fujian Province, shouldering the dissemination of Minnan culture, the sea silk culture of the task. To create a unique brand of free trade area, shaping the Fujian FTA cultural brand, to achieve from the introduction of "policy" to go out "strategy" a complete conversion. Fujian Province should form a new model of the development of the new free trade area, which is the development strategy of the economy first and the culture, which can not only "seek the road" but also "profit".

Fujian FTA branding strategy we cited the consumer psychology to build a new model ----AIGAS model to build. In the consumer psychology research level for the establishment of the brand in 1998, the American advertising scientist ES Lewis proposed AIDMA model, but with the development of technology and technology, especially the emergence of new media, the model in the improvement of the Japanese electrical group in 2005 Year proposed a more advanced brand building and consumer psychology to build a new model ----- AISAS. The model contains Attention (interest) - Interest (interest) ---- Search (independent search) ----- Action (behavior) ----- Share (sharing experience). The model used in Fujian Free Trade Area for the FTA brand promotion has a great theoretical basis and realistic decision-making guidance. In this paper, we make a part of this model of innovation and the model contains Attention (interest) - Interest (interest) ---Globalization (global localization) ----- Action (behavior) ----- Share experience. The third part of the search (independent search) changed to Globalization global localization, free trade area as an international window, shoulder the important responsibility of cultural exchanges, but the cultural mix will inevitably lead to the decline of traditional local culture, so for the Fujian Province FTA local culture to play a leading role in culture, thus establishing a free trade zone in Fujian Province, the unique cultural brand charm.

AIGAS model application of the first two parts focus on the Fujian Free Trade Area of nterest and interest is the spiritual culture of the construction and shape, in the localization of the behavior of foreign marketing strategies and local culture can be better combined with the local culture of the people High awareness of the characteristics of the rapid accumulation of public awareness for the Fujian FTA brand awareness. Feedback of public behavior is an extension of the value of the brand, based on large data of public behavior statistics and in turn can help Fujian FTA brand decision optimization and spiral upgrade. The sharing and output of the people is the embodiment of the cultural power of Fujian cultural personality, and finally the cultural brand structure of Fujian Free Trade Area. Finally, the cultural brand of Fujian Free Trade Area is unified and cultural output is unified. And finally establish a free trade area in Fujian Province, the unique quality of cultural brand image.

\section{Fujian Province Free Trade Area Visual Recognition System Remodeling Strategy}

The first part of the AIGAS model is Attention, so in the era of Internet technology, the visual recognition system has become a cornerstone of brand building. Visual behavior will affect the people's understanding, consumption, dissemination of the overall brand awareness, so as to establish the trust of the brand, fully accept the brand passed the core values and cultural characteristics. Therefore, the formation of the visual brand of the free trade area must be in the "shape" level, the traditional culture of architecture, clothing, color, food as the basis for visual design, the formation of a complete visual image recognition system.

The Publicity Visual System. In the free trade area publicity visual system, the Shanghai Free Trade Area has achieved some results, the Shanghai Free Trade Area in the official website has been part of the image of the shape, produced a series of free trade area popular information comic, but still Lack of complete visual integrity. So the Fujian Free Trade Area in the establishment of the beginning should be based on the local cultural characteristics of Fujian Province to build. Fujian traditional culture visual reconstruction focuses on the logo, the core values of slogans, as well as the image of the popular image, and completes supporting guided system.

At present, the overall national trade festivals of cultural brands are still only in the initial stage, 
the establishment of the cultural brand value of the free trade area has not been the corresponding attention and construction. So Fujian Province should be in the free trade area brand construction to first, so as to create a real free trade area in Fujian Province brand value, the formation of a unique cultural brand segment, establish a complete core values.

Through the comparison of the above table, the Fujian Provincial Free Trade Area visual identification system is not perfect, the need to build a complete visual identification system, the need to apply in the free trade area outside the publicity website, promotional materials, and settled in the enterprise Logo and so on to enhance the brand identity of the park. In the process of brand visualization, the "traditional culture prototype" multi-level innovation, mining "prototype" social value and commercial value is very necessary, the Fujian Free Trade Area to create a cultural business card, so that people change the free trade area Just buy a single image of duty-free items. So that the image of Fujian Free Trade Area from the simple trade and shopping, to multi-functional service changes in the form of change. So that the Fujian Provincial Free Trade Area to form a more close to the people, to human services as the main new image, thus forming a large number of people eye economy, improve the cultural brand to enhance the integrated image of the image.

The Traffic-Oriented Visual System. Fujian Province, three areas of the visual guide system is not perfect, in Xiamen and Haicang area for the investigation found that the current free trade area guided system failed to form. Especially in Fujian Province, the free trade area is divided into three areas, very fragmented if there is no complete color segmentation and clear instructions system will greatly increase the people looking for costs, then the first step of the AIGAS model to strengthen the identification of the FTA culture. This has led to a large number of people in the time the cost of waste, and for the first service to the free trade area user experience did not get better branding, and cultural penetration. We need to complete the shaping of the free trade area of the visual system (Figure 3), and the visual system into Fujian Province, a unique regional culture, to be able to three areas of zero, to enhance the tourism economy, shopping experience, trade deal brand attention, which will AIGAS model of the first stage of attention to the maximum.

\section{Fujian Province FTA Cultural Image Remodeling Strategy}

The second part of the AIGAS model is Interest (interest), Fujian traditional culture is the key to the formation of public attention. Fujian Province, the regional trade area of large areas scattered, scattered in three regions, Fuzhou regional traditional cultural brands have Tan Shanshan culture, boat culture, three square seven Lane culture, Shoushan stone culture four major cultural brands. The four traditional characteristics of Fuzhou culture has a rich public foundation brand enjoys popular support, with a strong brand awareness. Pingtan area of traditional culture, including marine culture, characteristics of Fujian and Taiwan culture, as well as numerous myths and legends, such as dumb emperor, live lions, cattle mountain king - sea salt legend, Bihu said odd, Pingtan seaweed and so on. Xiamen as a tourist city, the traditional culture of Fujian, Fujian and Taiwan culture is also extremely far-reaching impact. Due to the rich traditional cultural foundation of Fujian Province, it has formed a certain value of cultural cognition brand, so the value of remodeling becomes more prominent. The remodeling of traditional culture can form a more complete and more centric cultural core values.

Through the form can be seen, Fujian Province, the traditional culture has a great uniqueness and influence. In the AISAS model, the second part is Interest (interest), Fujian Province has its own traditional culture itself has a great cultural charm and Fujian traditional culture is the Fujian FTA characteristics of the brand. In the process of remodeling cultural brand in the free trade area, the expression of the form of "shape God", "God both" heritage and carry forward the design method. The traditional culture through different levels of traditional cultural and artistic activities, combined with modern means of expression, through the traditional cultural activities of subdivision, can make the traditional brand boost Fujian FTA brand core values of the formation. Segmentation and reconstruction of traditional culture in Fujian Province can be divided into traditional recreational activities and traditional objects.

Fujian Traditional Performing Arts Reengineering. Traditional cultural performances need to 
integrate into the modern stage art means, such as the integration of sound and light, the classical and modern time and space across the connection to form a complete form of performance and performance of the reconstruction, the public to form a visual appreciation of the habit, thus The Fujian Provincial Free Trade Area brand characteristics and fun full expression. In the subdivision of cultural activities need to cultural content into the FTA brand culture, so that the core values through cultural activities, through the soft implant method, into the people's cognitive and living habits. Traditional creative arts content innovation is the core, Fujian Province, the core values of the free trade area, the need for traditional performance art form of boost, in order to allow more people to understand the Fujian FTA spiritual culture construction of the unique.

Fujian Traditional Objects Recycling. The reorganization of traditional objects is more traditional diet, artifacts through modern design means, re-shape, leaving its charm, pass its characteristics, but also to combine the modern way of life. For the traditional old name of the re-packaging and design, as well as the traditional characteristics of the regional culture of the creation and design, are free trade area of Fujian Province, the traditional creation needs to introduce the design concept. Especially for the development and construction of traditional tourist souvenirs, the use of free trade area produced brand to shape the unique positioning of the free trade area attitude, the formation of more affinity of the people connected to create a free trade zone in Fujian Province, the unique cultural brand segment.

Traditional Behavior Habit Recycling. In addition to the cultural activities of the subdivision, the traditional creation, but also through visual behavior shaping, so that people form a habitual cultural and visual image of the overall image, through cultural visual perception to form a complete brand awareness, thus affecting the people of the consumption habits, to deepen the Fujian FTA brand values of identity. (Figure 5) to the public on the FTA brand attention and interest, then the Fujian Provincial Free Trade Area of the core values of the establishment will be able to produce great cohesion and brand centripetal force. The core of the traditional culture is to promote the rapid establishment of the brand characteristics of the cornerstone of the core values of the brand to help the Fujian Provincial Free Trade Area of credibility to build the core competitiveness of the brand, Upgrade the brand status. Fujian FTA's core values of the establishment of the focus is "connected with the people", Fujian traditional culture a wide range of mass base, so the rebirth of the strategy to allow people in the shortest time to form brand awareness.

\section{Taiwan Cultural Innovation Brand Management Model "in the Localization" Strategy}

AIGAS model of the third part of the search (independent search) in this part of the model for the model has a part of the innovation, the part of the search into a global culture in the localization, localization of the characteristics of the promotion (Globalization). Taiwan cultural studies in the localization originated in November 1998 to set up the Taiwan Cultural Research Society. Professor Chen Guangxing, a leader of Taiwan's cultural studies, also pointed out that "cultural studies should be highly grounded and should be connected with their own living space." Taiwan has a rich accumulation of cultural studies. The unique geographical position of the free trade area makes it very frequent to communicate with Taiwan's cultural innovation industry. It is not enough for the local brand of Taiwan to be imported and built, and it is necessary to enhance the local brand of Fujian Province in the regional brand characteristics, the need to form a new model of the Fujian Provincial Free Trade Area localized brand. Using Taiwan's brand of advanced management mode, to create a free trade area of its own local brand awareness, is to enhance the overall image of Fujian Free Trade Area key. We need to Taiwan cultural and creative brand operating experience into the free trade area to hatch the local cultural innovation brand, so as to promote the overall brand image of Fujian Province, the identification of brand image, and reputation, so through Taiwan's unique business model for Fujian Province, district in the international community to form a complete brand image, so that people can naturally concerned about the Fujian Provincial Free Trade Unique cultural charm.

The current Fujian Free Trade Area has made some achievements in the mode of cooperation with Taiwan. Xiamen Haicang Free Trade Zone, under the leadership of President Chen Xinzhong, 
called on the 17 members of the Taiwan Association to raise 3 million members in 2016 In May the establishment of Taiwan Peng investment management company to invest in Taiwan Venture Hall, an area of 13576 square meters. Planning three months to build the Taiwan Pavilion, the future will be more multi-point museum development prospects. Purpose: The transformation of the generation, the second generation of entrepreneurship, Sanju newcomer, to help Taiwan youth to the mainland development and entrepreneurship, effectively promote cross-strait youth exchange and integration. And set up, Taiwan-related prosecution service stations, Xiamen City, Taiwan youth employment entrepreneurship training base, cross-strait volunteer alliance training base, the Straits women's employment base.

Through the table of Taiwan policy analysis, the current Fujian FTA strategy focused on the introduction of trade policies to attract young talent from Taiwan to start business, as well as the sale of Taiwan's own local brand-based. But for the Taiwan cultural and creative industries in the "localization" brand building still need to have a better solution strategy.

Taiwan's New Cultural Talent Training Model "in the Localization" Strategy. Taiwan cultural industry education model not only has the traditional culture of the East basic education, but also have the international comprehensive ability of training. At present, the business and education of Taiwan's academic industry are the training and training of cultivating innovative talents. The model of lifelong learning is worth learning and learning from us. Learning from the "learn --- create ---- sell ---- camp" four-step strategy, the development of Taiwan's original cultural brand enhance the cultural connotation of the original cultural brand and the brand value of the market. We do not only need to introduce Taiwan's "Eslite Bookstore," Taiwan's own brand, more is to learn and follow the operating model of Taiwan's Wencuang to shape and incubate Fujian's own cultural brand. We need to use the Fujian Provincial Free Trade Area of the unique geographical advantages, as well as flexible and free policy and strategy to jointly create a culture of talent training model for the development of free trade area to provide talent, while education innovation is bound to enhance the Fujian Free Trade District of the overall brand reputation awareness. For the free trade area enhance the cultural brand to provide the basis for talent reserves.

Taiwan's New Cultural Brand Operating Model "in the Local" Strategy. Fujian Free Trade Area in May 2016 made a lot of results, but in addition to the introduction of cultural brand marketing, but also need to go out to form a complete international business card and brand image. Taiwan Cultural innovation brand operating mode in the localization strategy promotes the Fujian Provincial Free Trade Area brand culture output Fujian FTA policy should be more to Taiwan has a wealth of operational experience to give enterprises to tilt, to support. At the same time also special support for some of Taiwan's creative entertainment business, commissioned by the development of Fujian FTA characteristics of the entertainment products, the use of Taiwan's advanced brand operating model, through the free trade area of foreign enterprises, personnel, the use of Taiwan and foreign industries chain to form a complete "localized" brand of cultural output. Local regional characteristics of the old, local unique cultural brand lack of international vision of the means of operation, from Fujian to go out to enhance the Fujian Provincial Free Trade Area brand characteristics. Fujian Free Trade Area as an important starting point for the wire, the need to shoulder the introduction of the process to go out. Ming and Qing Dynasties Fujian as a cultural window of the boat culture, porcelain culture, the temple of the religious culture spread to the world, so the Fujian Provincial Free Trade Area as a new era of the window should take a new era of cultural transmission not only the trade, economic window, but also the window of cultural transmission, the unique culture of Fujian through the free trade area of trade and economic spread to the rest of the world, so that the Fujian Provincial Free Trade Area in the international image and international status are higher the promotion.

\section{Fujian Province Free Trade Area Three-Dimensional Digital Marketing Strategy}

In the AIGAS model, how to get people to Action (Action), Share (share experience) is the most important part of the marketing model, with the development of Internet technology, network media audience base rising, so that the network media has become a brand marketing The main channel of 
transmission, multi-screen merger of the base to promote the multi-point, multi-angle accurate spread of new ways. January 16, 2012, China Internet Information Center (CNNIC) released the "29th China Internet Development Statistics Report" shows that by the end of December 2011, the size of Chinese Internet users exceeded 500 million, reaching 513 million new Internet users throughout the year 55.8 million, the Internet penetration rate than the end of 2010 increased by 4 percentage points to $38.2 \%$. Chinese mobile phone users reached 356 million people; Chinese smart phone users reached 380 million people, Chinese mobile Internet market output value reached 712.5 billion RMB. From Ai media data

Pc-Side Network Media Help the Overall Platform Image Shaping of Fujian Province Free Trade Area. Fujian FTA's current official website, has made a certain result of the building, has been integrated in Fujian three scattered free trade area, to achieve the network integration. But as the most direct free trade area network media, the current official website to the text of the standard publicity and functions of the simple functions and obviously cannot fully reflect the Fujian Provincial Free Trade Area of the unique characteristics of the brand.

Through the analysis of the official website of the official website, it is found that the official website lacks the overall visual integration brand image and the promotion of the unified core values, the need to add the regional identity symbol on the website, and the cultural promotion of the core price view, establish platform service The new website of Fujian Free Trade Area, to the official website to create a network service hall, cultural brand building, upstream and downstream enterprises linked to the Fujian Provincial Free Trade Zone, a comprehensive marketing platform. Set of functional services, brand building, industrial chain construction, three regional integration, free trade area construction of multi-functional service-oriented government platform. So that the official website really do convenience, benefit the people, to enhance the Fujian Free Trade Area brand trust. Through the construction of the platform to establish a free Fujian FTA unique network marketing model, quickly opened with other regional free trade area of the brand segment, the use of new media technology to form the advantages of online industry integration, line industry gathered a new self Trade area marketing model. The formation of technical support, the site set up, cultural services leading the Fujian Provincial Free Trade Area brand new image.

The Mobile Side Dynamic Marketing Helps Fujian Province FTA Brand Memory. In the AIGAS model, Share (share experience) is the result of the final brand effect. Mobile application technology continues to develop, for the brand precision marketing to establish a solid user base. Mobile side of the more interactive touch points, so that brand marketing tools can be diversified, dynamic. The dynamic mobile marketing means is beneficial to the accumulation of MOT in the Fujian Free Trade Area, so as to achieve the accumulated branding effect of information transmission. Fujian Free Trade Area can be used in the area of large traffic static advertising and mobile terminal AR information expansion technology integration, through the mobile phone user scanning in the form of traditional paper media information for information expansion. So that the user's mobile phone side can show the Fujian Provincial Free Trade Area of the more three-dimensional three-dimension map, video information, cultural activities and other related dynamic three-dimensional information, thereby enhancing the Fujian Provincial Free Trade Area brand memory, brand deepening effect. In the user scan at the same time, the user will automatically download the information, the information through the phone to take home, to achieve the precise transmission of end users. When the user scans, the terminal of the FTA in Fujian Province can also calculate a large number of dynamic user information base. The information data can provide detailed data for the future economic development and legal decision-making of Fujian Free Trade Area. In the mobile media AR technology under the help of the formation of comprehensive three-dimensional seamless brand coverage, so it is more profound and dynamic to enhance the Fujian FTA's unique brand marketing a new image.

\section{Conclusion}

Fujian Province Free Trade Area in the construction process of a year from the policy, infrastructure, laws and regulations and many other results, but in the brand building aspects are 
still relatively weak, this paper cited a new model of consumer psychology - --- AIGAS model to build the Fujian Provincial Free Trade Area of the unique cultural brand image. From the professional brand building strategy to start, through five steps, four angles to shape the Fujian Provincial Free Trade Area of the integrated brand value. And provide some suggestions and references for the long-term sustainable construction of the FTA in Fujian Province. So that the local culture of Fujian Province, Fujian Province to become the cornerstone of the construction of cultural brand culture, Fujian FTA to improve the economy to provide some help. From the strategic height of the entire Fujian Provincial Free Trade Area image of the precise positioning in the process of internal and external communication to maintain a unified brand of independent trade brand image, to enhance the Fujian FTA cultural brand in the domestic and international influence, Thus enabling the Fujian Free Trade Area to harvest a huge global dividend.

\section{Acknowledgements}

Fund Project: Fujian province social science planning project "Fujian cultural industry transformation strategy research" (project number: FJ2016B100)

Fujian Province middle-aged and young teachers education and scientific research project "Fujian Free Trade Park cultural brand shaping strategy" (project number: JAS160778)

\section{References}

[1]. Wang Nannan. Construction machinery group buy streaking [J]. Today's construction machinery, 2012 (05)

[2] .Bei Jianxue Han Gongshu. College students use the network resources of the status quo analysis [J]. Technology Information, 2012 (05)

[3] .Chen Minghe, Wei Yannan. Expand the information consumption to promote the transformation of Chinese economic development mode [J]. Journal of Liaoning Administration College 2015 (04)

[4] .Ning Lili; Chen Xingyu. Investigation on the Current Situation of Media Literacy of College Students in Dali University under the New Communication Environment[J]. Journal of Bengbu University .2014 (04)

[5]. Tian Tao. Changes in the media ecology and the dissemination of gold resources[J]. Advertising Grand (Edition). 2012 (08)

[6]. Zhao Jianhua. Network environment, television editors should have the quality and ability [J]. Friends of Science. 2012 (06)

[7] .You Yuru. "Social Dependence" in Modern Society from the Perspective of Sociology [J] .Jiangnan Literature (Classics) .2012 (06)

[8]. Li Wei. Information age traditional TV media challenges and challenges [J]. China Radio and Television Technology Essence. 2013 (02)

[9] .Fan Lu-rong. Small and medium-sized publishing enterprise digital development strategy[D]. Beijing Printing Institute Master's thesis 2014 (01)

[10]. Wu Dai flaw network sales insurance on the legal disputes [C]. Zhejiang Province in 2013 insurance law academic annual conference Proceedings .2013 (11)

[11]. Geng Yiping. Zoom out the value of the Shanghai Free Trade Area to bring up [J]. Resource regeneration .2014 (10) 